\title{
Management of Transverse Vaginal Septum by Vaginoscopic Resection: Hymen Conservative Technique
}

\section{Manejo do septo vaginal transverso por ressecção vaginoscópica: técnica conservadora do hímen}

\author{
Gennaro Scutiero ${ }^{1}$ Pantaleo Greco ${ }^{1}$ Piergiorgio lannone ${ }^{1}$ Giulia Bernardi ${ }^{1}$ Francesca Greco ${ }^{2}$ \\ Luigi Nappi ${ }^{2}$ \\ ${ }^{1}$ Department of Morphology, Surgery and Experimental Medicine, \\ Section of Obstetrics and Gynecology, University of Ferrara, Azienda \\ Ospedaliero-Universitaria S. Anna, Cona, Ferrara, Italy \\ Address for correspondence Piergiorgio lannone, MD, Azienda \\ Ospedaliero-Universitaria S. Anna, Via Aldo Moro 8, 44121, Cona, \\ Ferrara, Italy (e-mail: pg.iannone88@gmail.com).
}

2 Department of Medical and Surgical Sciences, Institute of Obstetrics and Gynecology, University of Foggia, Foggia, Italy

Rev Bras Ginecol Obstet 2018;40:642-646.
Abstract
Keywords
- transverse vaginal septum
- hysteroscopy
- hematocolpos
- laparoscopy
- vaginal anomaly

Transverse vaginal septum is a rare female genital tract anomaly, and little is described about its surgical treatment. We report the case of a patient who wished to preserve hymenal integrity due to social and cultural beliefs. We performed a vaginoscopic resection of the septum under laparoscopic view, followed by the introduction of a Foley catheter in the vagina, thus preserving the hymen. After 12 months of follow-up, no septal closure was present, and the menstrual flow was effective. Vaginoscopic hysteroscopy is an effective method of vaginal septum resection, even in cases in which hymenal integrity must be preserved due to social and cultural beliefs.

Septo vaginal transverso é uma anomalia rara do trato genital feminino, e pouco é descrito sobre o tratamento cirúrgico. Relatamos o caso de uma paciente que desejava preservar a integridade do hímen devido a crenças sociais e culturais. Realizamos ressecção vaginoscópica do septo sob visão laparoscópica, seguida da introdução de um cateter de Foley na vagina, preservando assim o hímen. Após 12 meses de acompanhamento, não havia fechamento do septo, e o fluxo menstrual era eficaz. A histeroscopia vaginoscópica é um método eficaz de ressecção dos septos vaginais, incluindo os casos em que a integridade do hímen deve ser mantida devido a crenças sociais e culturais.

\section{Introduction}

Transverse vaginal septum (TVS) is an uncommon anomaly of the female genital tract whose incidence ranges from 1:2100 to $1: 84000 .^{1-3}$

received

March 29, 2018

accepted

June 27, 2018
DOI https://doi.org/

$10.1055 / \mathrm{s}-0038-1670714$ ISSN 0100-7203.
The etiology of this embryologic anomaly is still unknown; this anatomical condition is linked to autosomal recessive transmission, but, in most cases, a genetic origin cannot be found. ${ }^{4}$

Physiologically, the sinovaginal bulbs invaginate from the urogenital sinus and meet the Müllerian tubercle on the

Copyright @ 2018 by Thieme Revinter

Publicações Ltda, Rio de Janeiro, Brazil

License terms

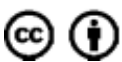


caudal end of the Müllerian ducts to form the vaginal plate that is then canalized to form the lower part of the vagina. ${ }^{5}$

Transverse vaginal septa are thought to result from a failure in the canalization of the vaginal plate at the point where the urogenital sinus meets the Müllerian duct. ${ }^{1}$

Genitourinary and gastrointestinal tract anomalies might be associated with TVS, such as: imperforate anus, malrotation of the gut, ectopic ureter with hypoplastic kidney, hydronephrosis, vesicovaginal fistula, and bicornuate uterus. ${ }^{6,7}$ Rare defects include musculoskeletal defects, aorta coarctation and atrial septal defect. ${ }^{7}$

Transverse vaginal septum can develop anywhere in the vagina, and its more common locations are the upper part of the vagina, the junction between the vaginal plate and the caudal end of the fused Müllerian ducts. ${ }^{1,2}$ Rock et $\mathrm{al}^{7}$ observed that $46 \%$ of septa were located in the upper vagina, $35 \%$, in the middle, and $19 \%$, in the lower vagina.

Imperforate septa usually present during adolescence with symptoms such as cyclical abdominal pain, obstructed menstruation, hematocolpos, and, occasionally, urinary retention. ${ }^{1}$ Hematocolpos is defined as a distended vagina filled with menstrual blood; hematometra is a term used to describe the distended uterus filled with blood caused by extreme accumulation of menstrual products. ${ }^{8}$

The diagnosis is suspected when an abdominal or pelvic mass is palpated, or when a foreshortened vagina is encountered and the cervix cannot be identified. ${ }^{1}$ Clinical examination, ultrasound, and magnetic resonance imaging (MRI) are all used in the diagnosis, and the MRI is useful before the surgery to determine the thickness and depth of the septum., ${ }^{9,10}$

A review of the literature suggests that ultrasound is still the primary diagnostic tool used, while the MRI is particularly useful to delineate more complex gynecologic anatomies. ${ }^{11,12}$

In the literature, several approaches are described, but none seems to be better than the others. ${ }^{1}$
It is deeply important to recognize as early as possible the disease to prevent patient complications, including endometriosis, hydronephrosis, possible pyelonephritis and superinfection that will cause sepsis. Moreover, the surgery should be performed by an expert and educated team with the goal of restoring the regular anatomy and physiology of the patient. ${ }^{13}$

We present a case of transverse vaginal septum in which the patient and her family expressed the strong desire to preserve hymenal integrity due to a sociocultural belief. We propose the management of the septum with vaginoscopic resection using a hysteroscope, under laparoscopic control, followed by the introduction of a Foley catheter in the vagina.

\section{Case Description}

A 14-year-old virgin girl presented to the emergency department complaining of severe hypogastric pain. She presented suprapubic fullness, but did not present abdominal distension or other symptoms.

Despite the presence of secondary sexual features, she had never had menarche, and had a history of cyclical pelvic pain.

Upon examination, she had a tender suprapubic mass, palpable almost $2 \mathrm{~cm}$ under the umbilicus. A rectal examination revealed an anterior mass. An abdominal ultrasound revealed a distended uterus and a vagina filled with a homogenous thick fluid; a diagnosis of hematocolpometra was made ( - Fig. $\mathbf{1}$ ).

An MRI was performed, and it showed proximal vagina and uterine distension, especially involving the cervix. The vagina appeared to terminate in a low complete transverse septum, $\sim 3 \mathrm{~cm}$ from the vaginal introitus, with a 7-mm thickness. No other abnormalities were detected (-Fig. 2).

The patient and her family refused vaginal surgery to preserve hymen integrity due to a sociocultural belief. After counselling about performing the vaginoscopic resection of

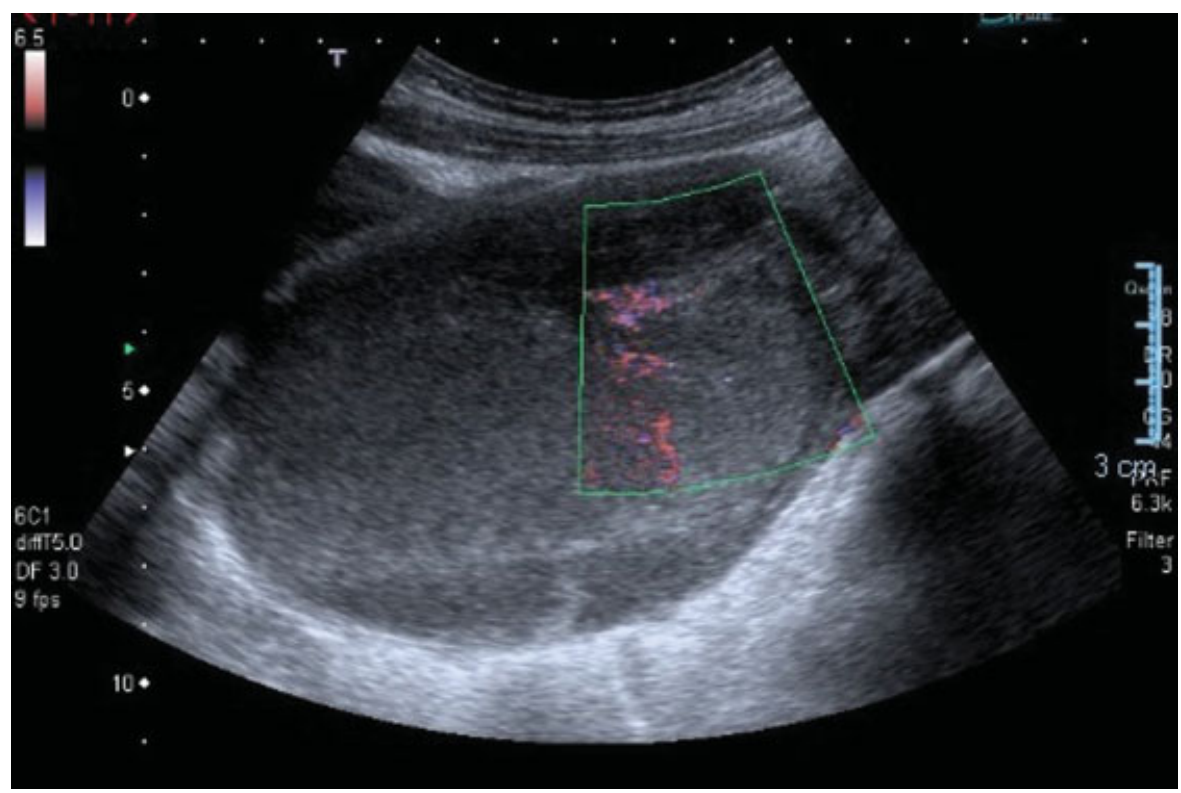

Fig. 1 Abdominal ultrasound showing a distended uterus. 


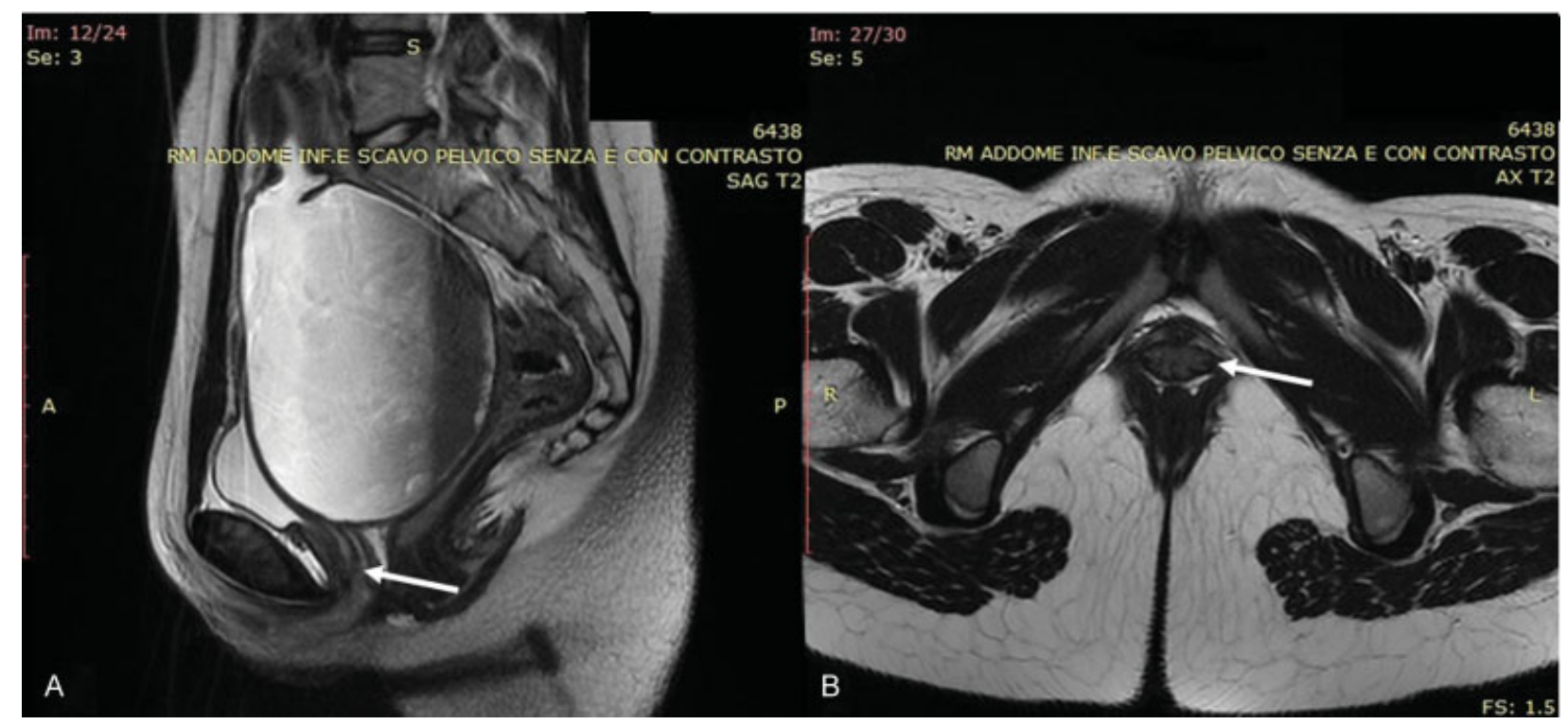

Fig. 2 (A) Sagittal view of the magnetic resonance imaging scan: hematocolpometra and level of the septum (arrow); (B) transversal view of the septum (arrow).

the septum using a hysteroscope under laparoscopic control, the patient and her family provided written informed consent for the procedure.

During laparoscopy, the uterus looked anteverted and enlarged. Both ovaries were normal. No endometriosis was detected.

The vagina appeared grossly distended, obliterating the Douglas pouch. A 5-mm office hysteroscope (Bettocchi Office Hysteroscope, Karl Storz GmbH \& Co., Tuttlingen, Germany) was introduced through the hymenal opening according to the vaginoscopic approach technique. ${ }^{14,15}$ The vaginoscopy revealed a bulging complete TVS. A 5-F bipolar electrode (Versapoint Bipolar Electrosurgical System, Gynecare, Ethicon, Inc., Somerville, NJ) was introduced through the operative channel of the hysteroscope, a bipolar electroresection of the septum was performed, and $300 \mathrm{~mL}$ of dark, old blood was evacuated. A Foley catheter was introduced from the introitus toward the septal perforation, and the balloon of the catheter was insufflated with $15 \mathrm{ml}$ of fluid. The patient recovered well from the surgery, and was placed on continuous oral contraceptive pills to suppress her menses and prevent hematocolpos reaccumulation.

She was dismissed three days after the procedure; a vaginoscopy was scheduled two months later, when the Foley catheter was removed. At the vaginoscopic examination, a fibrotic ring narrowing the vaginal canal was detected and completely resected with the bipolar electrode, without hymenal damage (-Fig. 3 ).

The patient was discharged on the same day, and underwent regular follow-up. The oral contraceptive pill was stopped four months later. The patient experienced regular menses and no other symptoms or discomfort 6 and 12 months after the last procedure. An abdominal ultrasound scan showed a normal genital tract ( - Fig. 4).

\section{Discussion}

One of the main causes of hematocolpometra is a complete vaginal septum. ${ }^{16} \mathrm{~A}$ transverse vaginal septum results from either incomplete canalization of the vaginal plate or failure of the paramesonephric ducts to meet the urogenital sinus. ${ }^{7,17}$

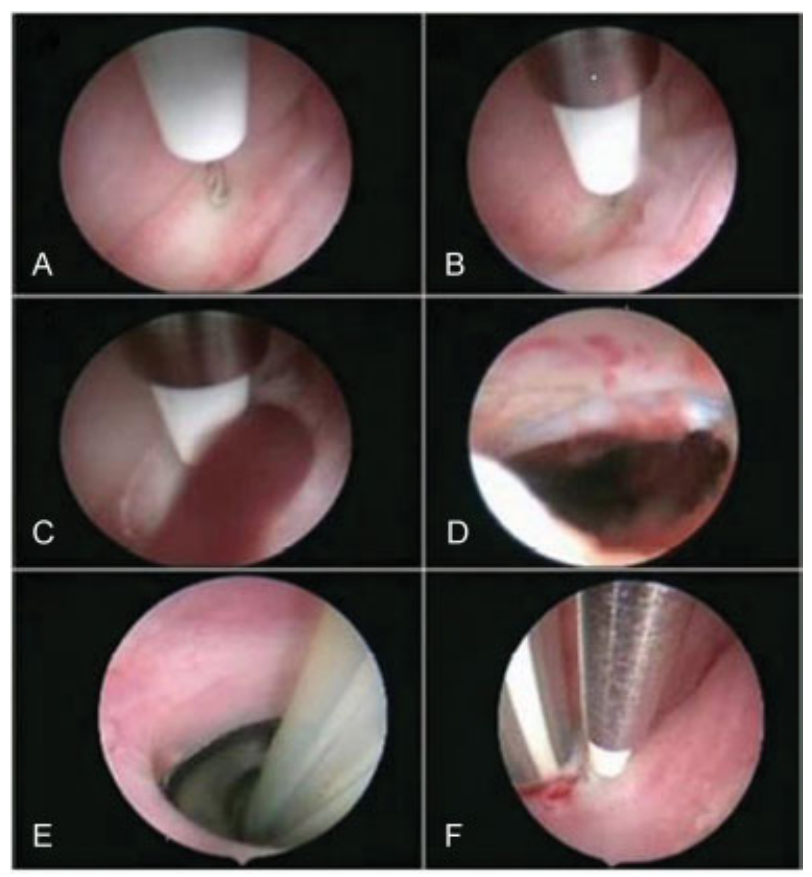

Fig. 3 (A-B-C-D) 5-F bipolar electrode introduced in the operative channel of the hysteroscope and bipolar electroresection of the septum performed with dark old blood evacuated; (E) Foley catheter introduced from the introitus toward the septal perforation and the balloon of the catheter insufflated with $15 \mathrm{ml}$ of fluid; (F) fibrotic ring resection with bipolar electrode without damage to the hymen. 


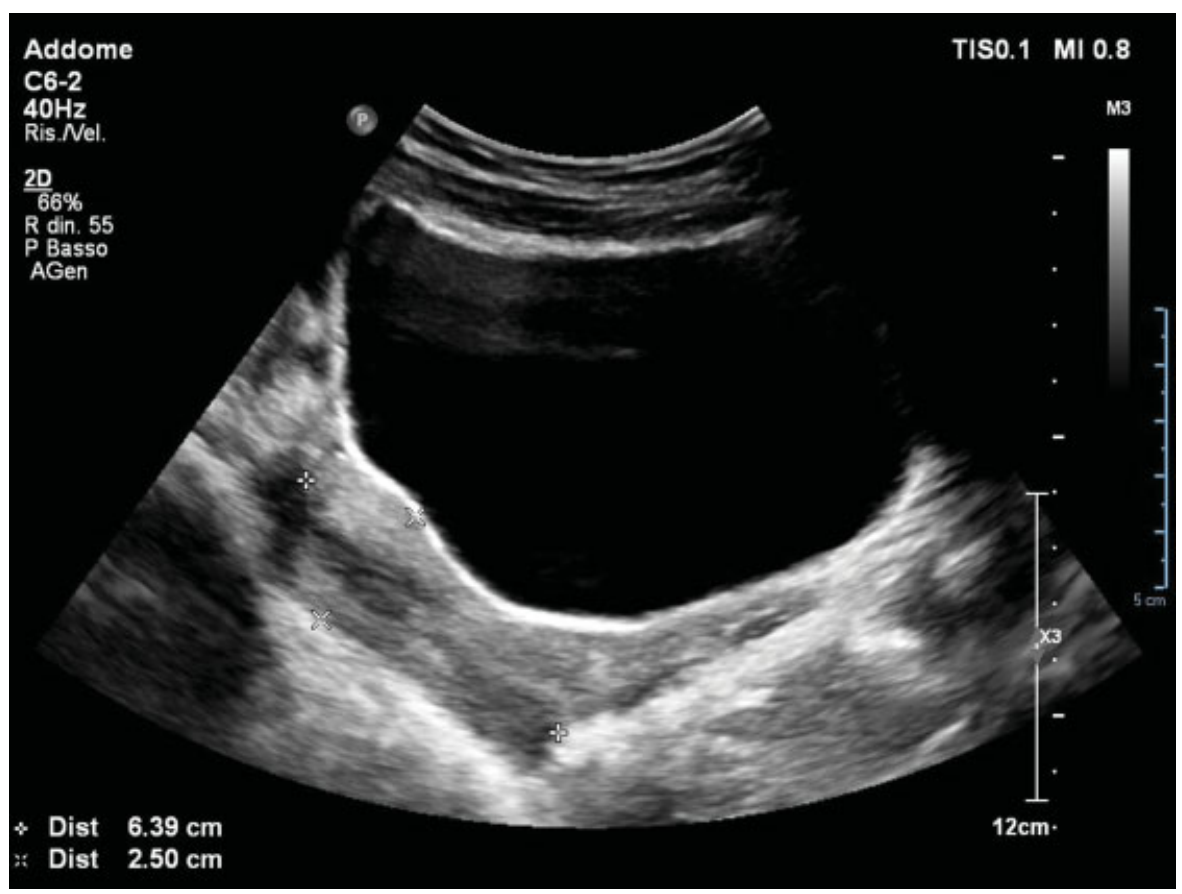

Fig. 4 Normal uterus on ultrasound after 12 months.

Very few data are available in the literature about the surgical management. The studies report on septum location, thickness and perforation. ${ }^{1,3,7}$

The location is also based on the distance from the vaginal introitus to the distal end of the septum, and it can be low $(<3 \mathrm{~cm})$, mid $(3-6 \mathrm{~cm})$, or high $(>6 \mathrm{~cm})$. About the thickness, the septum can be thin $(<1 \mathrm{~cm})$ or thick $(>1 \mathrm{~cm})$. In the presence of perforation, the thickness can usually be determined upon vaginal examination. In cases of imperforate septum, the thickness of the septum is measured via MRI. ${ }^{1}$

According to Dennie's et $\mathrm{al}^{18}$ experience, the septum has to be removed when the girl reaches the menarche age, and the operative intervention is easier if the patient presents with hematocolpos before its drainage. Williams et $\mathrm{al}^{1}$ described 46 patients affected by TVS treated in 3 different ways: abdominoperineal vaginoplasty via laparotomy, simple excision using the vaginal approach, and laparoscopic resection of the vaginal septum.

Another surgical approach is the Grünberger method, which consists of a cross-shaped incision on the caudal part of the septum, a cruciate incision on the cranial part, and transverse closure. ${ }^{19,20}$ Wierrani et $\mathrm{al}^{21}$ described good results in 13 patients treated with Grünberger modification of the Garcia Z plasty.

Van Bijsterveldt et $\mathrm{al}^{22}$ proposed two novel techniques for the treatment of the vaginal septum: the push through and pull through techniques. The first one requires a combined abdominal-vaginal approach, and it is used in patients presenting higher restenosis risk after surgery. The pull through technique is reserved for patients with a simple vaginal obstruction. ${ }^{22}$

A modification of this technique was performed by Layman et $\mathrm{al}^{23}$ with a pull through of a proximal distended vagina using an Olbert balloon catheter to facilitate the surgical management and to limit the postoperative narrowing of the vagina.

Vaginal septum may not be the only anatomical defect in a patient, but part of a more complex syndrome. Tug et $\mathrm{al}^{24}$ reported the case of a young patient affected by obstructed hemivagina and ipsilateral renal anomaly (OHVIRA) syndrome. In this case, the vaginal septum is completely incised by $\mathrm{CO} 2$ laser with hysteroscopy without hymenotomy, and the distal part of the septum is simply cut and sutured. ${ }^{24}$ Tehrani et al, ${ }^{25}$ also reported a single case of septum removal in a 19-year-old girl by resectoscope followed by hymenorraphy.

Sardesai et $\mathrm{al}^{2}$ described double cross plasty/Z plasty for the management of TVS after a 20 -year experience as a better technique compared with the other surgical methods.

Several surgical techniques have been described, but Kansagra et al ${ }^{26}$ proposed an alternative approach. A method of serial balloon dilation over a transvaginally inserted guide wire to create a durable outflow tract from the uterus to the lower vagina, without the immediate need of surgery. ${ }^{26}$

Postoperative complications, such as vaginal stenosis and reobstruction, can occur, especially when the septum is thick. ${ }^{3}$ To decrease the chance of stenosis, vaginal molds can be used; however these require the cooperation of the young patient, who may not be emotionally mature enough to use dilators faithfully. ${ }^{7}$

In our case, since the patient and her family rejected any vaginal approach to preserve hymenal integrity, which represents virginity according to the sociocultural values and traditions of their society, we developed an alternative method that would not damage the hymen.

The vaginoscopic approach allowed us to preserve the integrity of the hymen. The risk of stenosis may still be 
present, but the pressure applied by the balloon of the catheter on the septal perforation is expected to decrease the closure of the septum. After 12 months of follow-up, there was no septal closure, and the menstrual outflow was effective. The patient did not complain of other symptoms or of discomfort after 12 months.

\section{Conclusion}

In selected cases, with an intact outflow tract, vaginoscopy using a hysteroscope followed by the insertion of a Foley catheter could represent an effective method for the resection of vaginal septa, even in the case of virgin patients, because it is safe, effective, and easy to perform. The vaginoscopic approach should be used when performing hysteroscopy, but, above all, it should be considered as an alternative treatment in societies composed of ethnic groups that place importance on the integrity of the hymen.

\section{Contributions}

GS: design, data interpretation, surgeon; PG: data analysis, critical review, final approval; PI: data collection, writing of the article; GB: data collection, writing of the article; FG: data collection, writing of the article; LN: final approval, critical review of the intellectual content.

\section{Conflict of Interests}

The authors have none to declare.

\section{References}

1 Williams CE, Nakhal RS, Hall-Craggs MA, et al. Transverse vaginal septae: management and long-term outcomes. BJOG 2014;121 (13):1653-1658. Doi: 10.1111/1471-0528.12899

2 Sardesai SP, Dabade R, Chitale V. Double cross plasty for management of transverse vaginal septum: a 20-year retrospective review of our experience. J Obstet Gynaecol India 2015;65(03): 181-185. Doi: 10.1007/s13224-014-0542-3

3 Arkoulis N, Kearns C, Deeny M, Telfer J. The interdigitating Yplasty procedure for the correction of transverse vaginal septa. BJOG 2017;124(02):331-335. Doi: 10.1111/1471-0528.14228

4 Crosby WM, Hill EC. Embryology of the Mullerian duct syytem. Review of present-day theory. Obstet Gynecol 1962;20:507-515

5 Coskun A, Okur N, Ozdemir O, Kiran G, Arýkan DC. Uterus didelphys with an obstructed unilateral vagina by a transverse vaginal septum associated with ipsilateral renal agenesis, duplication of inferior vena cava, high-riding aortic bifurcation, and intestinal malrotation: a case report. Fertil Steril 2008;90(05): 2006.e9-e11. Doi: 10.1016/j.fertnstert.2008.05.030

6 Reed MH, Griscom NT. Hydrometrocolpos in infancy. Am J Roentgenol Radium Ther Nucl Med 1973;118(01):1-13. Doi: 10.2214/ajr.118.1.1

7 Rock JA, Zacur HA, Dlugi AM, Jones HW Jr, TeLinde RW. Pregnancy success following surgical correction of imperforate hymen and complete transverse vaginal septum. Obstet Gynecol 1982;59 (04):448-451

8 Deligeoroglou E, Iavazzo C, Sofoudis C, Kalampokas T, Creatsas G. Management of hematocolpos in adolescents with transverse vaginal septum. Arch Gynecol Obstet 2012;285(04):1083-1087. Doi: 10.1007/s00404-011-2114-4
9 Stadtmauer L, Shah A. Gynecologic surgery: preoperative assessment with ultrasound. Clin Obstet Gynecol 2017;60(01):82-92. Doi: 10.1097/GRF.0000000000000260

10 Noviello C, Romano M, Nino F, Martino A, Cobellis G. Clinical and radiological findings for early diagnosis of Herlyn-Werner-Wunderlich syndrome in pediatric age: experience of a single center. Gynecol Endocrinol 2018;34(01):56-58. Doi: 10.1080/09513590. 2017.1332178

11 Krafft C, Hartin CW Jr, Ozgediz DE. Magnetic resonance as an aid in the diagnosis of a transverse vaginal septum. J Pediatr Surg 2012; 47(02):422-425. Doi: 10.1016/j.jpedsurg.2011.10.056

12 Loscalzo IL, Catapano M, Loscalzo J, Sama A. Imperforate hymen with bilateral hydronephrosis: an unusual emergency department diagnosis. J Emerg Med 1995;13(03):337-339

13 Adali E, Kurdoglu M, Yildizhan R, Kolusari A. An overlooked cause of acute urinary retention in an adolescent girl: a case report. Arch Gynecol Obstet 2009;279(05):701-703. Doi: 10.1007/s00404008-0778-1

14 Bettocchi S, Ceci O, Di Venere R, et al. Advanced operative office hysteroscopy without anaesthesia: analysis of 501 cases treated with a 5 Fr. bipolar electrode. Hum Reprod 2002;17(09):2435-2438. Doi: 10.1093/humrep/17.9.2435

15 Indraccolo U, Greco P, Scutiero G, et al. The role of hysteroscopy in the diagnostic work-up of infertile asymptomatic patients. Clin Exp Obstet Gynecol 2014;41(02):124-127

16 Creatsas G, Cardamakis E, Hassan E, Deligeoroglou E, Salaros N, Aravantinos D. Congenital uterine anomalies with obstructed cervix, hemivagina, or both during adolescence: report of 22 cases. J Gynecol Surg 1994;10:159-167. Doi: 10.1089/ gyn.1994.10.159

17 Moore KL, Persaud TVN. The Developing Human: Clinically Oriented Embryology. 7th ed. Philadelphia: WB Saunders; 2003

18 Dennie J, Pillay S, Watson D, Grover S. Laparoscopic drainage of hematocolpos: a new treatment option for the acute management of a transverse vaginal septum. Fertil Steril 2010;94(05): 1853-1857. Doi: 10.1016/j.fertnstert.2009.09.041

19 Garcia RF. Z-plasty for correction of congenital transferse vaginal septum. Am J Obstet Gynecol 1967;99(08):1164-1165. Doi: 10.1016/0002-9378(67)90357-2

20 Blanton EN, Rouse DJ. Trial of labor in women with transverse vaginal septa. Obstet Gynecol 2003;101(5 Pt 2):1110-1112

21 Wierrani F, Bodner K, Spängler B, Grünberger W. "Z"-plasty of the transverse vaginal septum using Garcia's procedure and the Grünberger modification. Fertil Steril 2003;79(03):608-612. Doi: 10.1016/S0015-0282(02)04803-3

22 van Bijsterveldt $C$, Willemsen $W$. Treatment of patients with a congenital transversal vaginal septum or a partial aplasia of the vagina. The vaginal pull-through versus the push-through technique. J Pediatr Adolesc Gynecol 2009;22(03):157-161. Doi: 10.1016/j.jpag.2008.02.008

23 Layman LC, McDonough PG. Management of transverse vaginal septum using the Olbert balloon catheter to mobilize the proximal vaginal mucosa and facilitate low anastomosis. Fertil Steril 2010;94(06):2316-2318. Doi: 10.1016/j.fertnstert.2009.12.061

24 Tug N, Sargin MA, Çelik A, Alp T, Yenidede I. Treatment of virgin OHVIRA syndrome with haematometrocolpos by complete incision of vaginal septum without hymenotomy. J Clin Diagn Res 2015;9(11):QD15-QD16. Doi: 10.7860/JCDR/2015/15532.6826

25 Tehrani HG, Hashemi L, Ghasemi M. Complete bicornuate uterus with complete transverse vaginal septum. J Res Med Sci 2014;19 (04):378-379

26 Kansagra AP, Miller CB, Roberts AC. A novel image-guided balloon vaginoplasty method to treat obstructive vaginal anomalies. J Vasc Interv Radiol 2011;22(05):691-694. Doi: 10.1016/j.jvir.2011.01.432 